\title{
Personal-organisational value conflicts and job satisfaction of internal construction stakeholders
}

\author{
Babak Panahi ${ }^{1}$, Elena Moezzi ${ }^{1}$, Christopher Nigel Preece ${ }^{2}$ and Wan Normeza Wan Zakaria ${ }^{1}$ \\ ${ }^{1}$ Razak School of Engineering and Advanced Technology, Universiti Teknologi Malaysia (UTM), Malaysia. \\ ${ }^{2}$ College of Engineering, Abu Dhabi University (ADU), United Arab Emirates.
}

\begin{abstract}
This paper concerns the issue of value conflicts in construction organizations. This research was conducted in the Malaysian construction industry to fill the gap in the knowledge in areas of organizational behaviour in the construction industry in terms of the possible effects of conflicts on the job satisfaction of internal construction stakeholders. The conflicts considered are those rooted in differences between personal and organizational values. This research targeted professional project consultants identified as architects, engineers, and quantity surveyors as the internal construction stakeholders in Malaysia. The personal-organizational values and the level of job satisfaction of the stakeholders were assessed using a questionnaire survey. To achieve the research objective, comparative and hierarchical regression analyses were performed. The results generated by the analyses indicated a high level of value conflicts in the construction organizations which significantly and negatively affected job satisfaction of the internal stakeholders. Therefore this research, through investigating the potential effect of value conflicts on the stakeholders' job satisfaction, reveals the importance of the interaction between personal and organizational values in construction organizations which contributes to the extant literature of organizational behaviour in construction.
\end{abstract}

Keywords: Personal values, organizational values, conflict, job satisfaction, internal construction stakeholders.

Paper type: Research article

\section{Introduction}

Job satisfaction is one of the most important determinative factors of productivity and efficiency of organizations (Aziri, 2011). Evidence demonstrates that it is the case for construction organizations as well, because job satisfaction is considered as the predictor of several workrelated factors like performance, commitment, motivation and productivity, which are determinants of the success of construction projects (Sweis, 2010; Marzuki, Permadi and Sunaryo, 2012). Accordingly, for construction organizations it is imperative to focus on the stakeholders' job satisfaction, aiming to enhance it and eliminate factors that negatively affect it.

One of the unique characteristics of the construction industry is the multiplicity and diversity of the stakeholders involved in this sector (Femi, 2014). The fact that a project consists of several stakeholders from different backgrounds, ethnicity, and religion with different values, defines

\footnotetext{
Copyright: Construction Economics and Building 2016. C 2016 Babak Panahi, Elena Moezzi, Christopher Nigel Preece and Wan Normeza Wan Zakaria. This is an Open Access article distributed under the terms of the Creative Commons Attribution 4.0 Unported (CC BY 4.0) License (https://creativecommons.org/licenses/by/4.0/), allowing third parties to copy and redistribute the material in any medium or format and to remix, transform, and build upon the material for any purpose, even commercially, provided the original work is properly cited and states its license.
}

Citation: Panahi, B., Moezzi, E., Preece, C.N., and Zakaria, W. N. W. 2016. Personal- organisational value conflicts and job satisfaction of internal construction stakeholders, Construction Economics and Building, 16(41, 1-17. DOI: http://dx.doi.org/10.5130/AJCEB.v16i1.4811

Corresponding author: Babak Panahi; Email - pbabak2@live.utm.my

Publisher: University of Technology Sydney (UTS) ePress 
conflict itself (Femi, 2014). Therefore, as long as there are differences in values among stakeholders, conflicts are inevitable in construction projects (Fenn, Lowe and Speck, 1997).

Values are considered as the characteristics of both individuals and organizations (Schein, 2011). The extent to which personal values match with organizational values is considered to be an indicator of "fit" between the person and the organization which implies the concept of personorganization (P-O) fit (Thomas, 2013). P-O fit focuses on how the patterning and content of an individual's values, when juxtaposed with the organizational values prevalent in an organization, affect the individual's attitude and behaviour (Thomas, 2013). Empirical evidence indicates that an appropriate P-O fit enhances employees' job satisfaction in organizations (e.g., Tepeci, 2001; Karakurum, 2005; De Clercq, 2007).

Conversely, an individual with low levels of work-related interests and attributes may possess personal values that are incongruent with the value system of the organization. In such cases, friction between personal values and organizational values creates conflict (Drucker, 1988; Suar and Khuntia, 2010). Although the positive effect of P-O fit on job satisfaction has been well studied in the literature, nevertheless the opposite function of personal-organizational value conflicts on job satisfaction is a fundamental question in the extant literature of organizational behaviour (Jehn, 1997; Leung, Yu and Liang, 2013).

Furthermore, in the construction industry context there is a gap in the knowledge in terms of value conflicts and their possible effects on stakeholders' job satisfaction. Although the negative impacts of conflicts on construction project outcomes have been considerably investigated and discussed in construction literature (e.g., Brockman, 2012; Femi, 2014), the constructive or destructive effects of conflicts on the construction stakeholders' attitude and behaviour is an unclear issue (De Dreu and Van Vianen, 2001; Leung, Ng and Cheung, 2002). In a broad sense, the literature affirms that the conflict issue in construction projects has been typically investigated from the perspective of project outcomes, not the antecedent of conflicts (e.g., values) and the perspective of individual outcomes (e.g., job satisfaction). More specifically, in the Malaysian construction industry there is a lack of knowledge and effective investigation in terms of values, personally and organizationally (Hamid and Yahya, 2011). In addition, the research on the construct of conflict is also insufficient and significantly limited (Jaffar, Tharim and Shuib, 2011; Zouher Al-Sibaie et al., 2014; Adnan et al., 2012).

Therefore, according to the pivotal role of job satisfaction of construction stakeholders in projects' success; the conflicting atmosphere of construction industry; the determinative role of dissimilarity of personal and organizational values in explaining conflicts, and in order to fill the gap in the knowledge in the areas of organizational behaviour within the construction industry, specifically in Malaysia, this paper looks at the issue of personal-organizational value conflicts and their possible effects on job satisfaction of the internal construction stakeholders in Malaysia. Expressed more clearly, this research aimed to investigate whether personalorganizational value conflict is the predictor of job satisfaction of the internal construction stakeholders. As conflict in construction projects is perceived as a destructive phenomenon, this research hypothesized that there is a significant negative relationship between conflict and job satisfaction of the internal construction stakeholders.

\section{Literature review}

\section{Conflict}

Hellard (1988) considers conflict as a disagreement and opposition between people about something related to an individual's interests, values, beliefs, ideas, goals and needs. Conflict has been cited by numerous writers in the construction context (e.g., Brockman, 2012; Femi, 2014), 
but the authors have considered conflict from different perspectives such as conflict management styles applicable in construction projects, financial problems caused by conflict, conflict and dispute, potential ways to reduce conflict, and so on. More specifically in the Malaysian construction industry, studies which focused on the topic of conflict are very limited. Jaffar, Tharim and Shuib (2011) overviewed the factors of conflict in the construction industry and recognized three types of conflict factors: conflicts due to technical problems, contractual problems, and behavioural problems. Zouher Al-Sibaie et al. (2014) examined the relationship between conflict and performance in international construction projects. The findings indicated that conflict explained about $27 \%$ of the variance in project performance. Adnan et al. (2012) investigated the factors that cause conflicts and established ways of preventing or reducing conflicts in partnering in the Malaysian construction industry. All of the aforementioned studies have addressed conflict as a destructive phenomenon in construction projects, although none of them assessed the value antecedent of those conflicts and the possible effects of the value conflicts on attitudinal factors like job satisfaction of construction stakeholders in Malaysia.

\section{Personal-organisational values}

Schwartz and Bilsky (1987) defined values as "concepts or beliefs about desirable end states or behaviours that transcend specific situations, guide selection or evaluation of behaviour and events, and are ordered by relative importance" (p.551). Values are considered as the characteristics of both individuals and organizations. At the individual level, personal values in the work setting are defined as "what a person wants out of work in general and also what components of a job are important to his or her work satisfaction" (Duffy, 2010, p.52), or "beliefs about the desirability of specific outcomes of working" (Hattrup, Mueller and Joens, 2007, p.481). Personal values are more pervasive than work goals, and they indicate a person's general preferences toward his/her work life (Vansteenkiste et al., 2007).

At the organizational level, values are seen as the defining characteristics of the organizational culture (Schein, 2011). Williams (2002) argues that values are those elements of the context that describe characteristics of organizations (Chatman, 1991), guide action and behaviour (Williams, 1979) and serve to differentiate organizations (Rokeach, 1979). In general, organizational values are defined by their ability to affect and guide the selections, preferences, attitudes, and actions of the organization and its employees (Toh, Morgeson and Campion, 2008). The extent to which personal values match with organizational values is considered as the indicator of "fit" between personal and organizational patterns (Thomas, 2013). By contrast, the friction between personal and organizational values as the result of dissimilar patterns of values leads to conflict (Drucker, 1988; Suar and Khuntia, 2010).

Different measures have been used for evaluating personal and organizational values in the early studies of interaction between person and organization (Karakurum, 2005; De Clercq, 2007). In contrast, the literature presents "commensurate measurement" which enables the implementation of a common standard to measure personal and organizational values (Chatman, 1989). The popular instruments used for commensurate measurement include: the Organizational Culture Profile (OCP; O'Reilly, Chatman and Caldwell, 1991), the Organizational Values Congruence Scale (OVCS; Enz, 1988), and the Work-Organizational Value Survey (WOVS; De Clercq, 2007). These instruments operationalize organizational culture as respondents' perception. Therefore, firstly, the respondents were asked to determine to what extent each of the values are important for them, and secondly, to what extent each of the values are important in their organization. The first question indicates personal values, while the second question indicates organizational values. Then, personal and organizational values were compared to assess fit or conflict. 
The values' assessment is an embryonic topic in the context of construction industry. Although some scholars particularly focused on personal values of construction participants (e.g., Munson and Posner, 1979; Daniela et al., 2013), nonetheless the study by Thomson and Austin (2006) can be considered as the most specific attempt to assess values in construction projects. Thomson and Austin (2006) introduced VALiD (value in design) in the UK construction industry which is an approach to value delivery that integrates stakeholder judgment into the design process. It runs alongside existing project practices to provide insights into stakeholders' views of values (Thomson and Austin, 2006). However VALiD does not generalize the value perception and does not focus on the structure of value conflicts in construction organizations. In the Malaysian construction industry, the assessment of personal-organisational values is limited to the work of Hamid and Yahya (2011) which addressed the relationship between person-job (P-J) fit and person-organization (P-O) fit with employees' work engagement. They targeted engineers in seven semiconductor companies in Malaysia. It demonstrates to what extent the values' investigation in the Malaysian construction industry is limited.

\section{Job satisfaction}

Ivancevich, Olekalns and Matteson (1997) defined job satisfaction as "an attitude that individuals have about their jobs" (p.91). It is rooted in the individual perception of his/her job and the extent to which there is an adequate fit between individual and organization. Evidence demonstrates that job satisfaction plays a significant role in the construction context. Marzuki, Permadi and Sunrayo (2012) state that job satisfaction shapes many features of employees' behaviours towards their jobs, including motivation, productivity and performance which are pivotal to the success of construction projects and organizations. Furthermore, Sweis (2010) argued that job satisfaction is an essential factor for the success of construction organizations because it is tightly associated with performance and job turnover. As a corollary to this, the employees' job satisfaction must be one of the prime objectives of construction organizations.

In the values' literature, job satisfaction has been considered in P-O fit research. Tepeci (2001) investigated whether P-O fit contributed to explanation of employee's job satisfaction. The sample included 326 restaurant employees from 34 restaurants in the USA. Tepeci (2001) found a significant positive relationship between P-O fit and job satisfaction. In another study, Karakurum (2005) targeted 180 employees from a Turkish public organization and affirmed Tepeci's (2001) finding. Likewise, De Clercq (2007) proved a positive correlation between P-O fit and job satisfaction based on the data collected from 591 employees in 26 Belgian organizations. Accordingly, although the values' literature is rich from the studies which have focused on the relationship between P-O fit and job satisfaction, nevertheless the relationship between value conflicts and job satisfaction is still an unclear issue in the literature.

There are several approaches, scales and viewpoints to measure job satisfaction in the literature (Schmidt, 2007). Researchers working on this issue have developed several assessment models like: the Minnesota Satisfaction Questionnaire (MSQ; Weiss et al., 1967), the Job Descriptive Index (JDI; Smith, Kendall and Hulin, 1969), the Job Satisfaction Survey (JSS; Spector, 1997), and the Michigan Organization Assessment Questionnaire (MOAQ; Cammann et al., 1979), to assess employees' job satisfaction. One useful and popular model is the Job Satisfaction Survey (JSS) developed by Spector (1997). It is the most popular format in job satisfaction scales. This model discusses nine factors for job satisfaction including: pay, promotion, supervision, fringe benefits, contingent rewards, operating conditions, co-workers, nature of work, and communication.

Aside from the type of instrument for measuring job satisfaction, the interaction theory of Lewin (1951) offers another approach to this attitudinal variable. Lewin (1951) described human attitude and behaviour as the result of interaction between the characteristics of two 
interdependent factors: the person and the environment (Schneider, 2001). He recognized the importance of both the individual and the environment as powerful determinants of human attitude and behaviour (Kennedy, 2005). The person characteristics refer to individuals' psychological or biological needs, goals, values, abilities, or personality. On the other hand, the characteristics of environment include physical or psychological demands, intrinsic or extrinsic rewards, cultural values, or environmental factors like temperature, safety and convenience (Cable and Edwards, 2004).

The interaction theory of Lewin (1951) reveals the function of values in both personal and environmental factors (Bao, Dolan and Tzafrir, 2012). Values are the foundation of the individual's behaviour and attitude, and the organizational culture. More thoroughly expressed, personal values are an indicator of individuals' characteristics and organizational values are the indicator of organizations' characteristics in Lewin's (1951) interaction theory. Therefore, attitudinal and behavioural variables such as job satisfaction, organizational commitment, job performance, etc. can be explained by personal and organizational values (De Clercq, 2007; Bao, Dolan and Tzafrir, 2012). Accordingly, through selecting and matching values regarding several dimensions, content and items considered as reliable instruments for measuring attitudinal and behavioural variables, a commensurate measurement of personal and organizational values is able to measure the determined variables indirectly. This research implemented the method of value-based measurement to evaluate job satisfaction.

\section{Research method}

This research was conducted in quantitative method using a questionnaire survey. Indeed, personal and organizational values can be evaluated through both qualitative and quantitative methods. For example, personal values can be assessed by interview or observation. But as with the qualitative study of culture, understanding individual's values from their behaviour or interview responses is problematic because: 1) quantifying and interpreting values is difficult, 2) the researcher's or observer's personal values may affect the assessment, and 3) a person might not be willing or able to talk about his/her values, or might be selective in revealing them (Tepeci, 2001; Karakurum, 2005). In fact, qualitative measurement might be more useful for generating the list of values, once that list is established; quantitative instruments facilitate data collection and analysis, especially the comparisons of personal and organizational values.

\section{The instrument}

As mentioned before, one of the most popular and applicable instruments for commensurate measurement is WOVS which was structured on the basis of De Clercq's (2007) value model. De Clercq's (2007) comprehensive value model which was inspired by Schwartz's (1992) universal theory, comprises fifteen motivational goals or value types representing the values in work and organizational context (see Table 1).

These empirical types are ordered along four higher-order value types which form two bi-polar higher-order value dimensions that also imply value conflicts between pairs of values. The first dimension is openness to change versus conservation. Openness to change values (i.e. stimulation and self-direction) emphasizes independent actions, thoughts and feelings and a readiness for new experiences, whereas conservation values (i.e. tradition and security) imply selfrestriction, order and resistance to change (Sverdlik, 2012). The second dimension is selfenhancement versus self-transcendence values. Self-enhancement values (i.e. achievement and power) imply the pursuit of self-interest, whereas self-transcendence values (i.e. benevolence and universalism) refer to concern for the interests and welfare of others. The circular structure in Figure 1 displays the total pattern of relations of conflict among values postulated by the theory. 
Using the comprehensive De Clercq (2007) value model enables the instrument to find different relationships between personal values, perceived organizational values and fit or conflict. These qualifications of the De Clercq's (2007) value model were strongly compelling to conduct the current research based on that model. Therefore, the research instrument is an adapted version of the WOVS by De Clercq (2007) which was further developed and optimized. WOVS was developed to consider two important points: 1) the value set must be relevant to the characteristics of the construction industry, and 2) the value set must enable the instrument to measure job satisfaction indirectly and precisely.

Table 1: Definitions of the fifteen motivational types of values in terms of their goals

\begin{tabular}{|l|l|}
\hline \multicolumn{1}{|c|}{ Value } & \multicolumn{1}{c|}{ Definition } \\
\hline Achievement & $\begin{array}{l}\text { Personal success through demonstrating competence according to social } \\
\text { standards. }\end{array}$ \\
\hline Benevolence & $\begin{array}{l}\text { Preservation and enhancement of the welfare of people with whom one is in } \\
\text { frequent personal contact. }\end{array}$ \\
\hline Conformity & $\begin{array}{l}\text { Restraint of actions, inclinations, and impulses likely to upset or harm others and } \\
\text { violate social expectations or norms. }\end{array}$ \\
\hline Goal-orientedness & Living and working to fulfil a purpose, not giving up. \\
\hline Hedonism & Pleasure and sensuous gratification for oneself. \\
\hline Materialism & Attaching importance to material goods, wealth, and luxury. \\
\hline Power & Control or dominance over people. \\
\hline Prestige & Striving for admiration and recognition. \\
\hline Relations & Having good interpersonal relations with other people and valuing true friendship. \\
\hline Security & Safety, harmony, and stability of society, of relationships, and of self. \\
\hline Self-direction & Independent thought and action-choosing, creating, and exploring. \\
\hline Social-commitment & Preservation and enhancement of the welfare of all people. \\
\hline Stimulation & Excitement, novelty, and challenge in life. \\
\hline Tradition & $\begin{array}{l}\text { Respect, commitment, and acceptance of the customs and ideas that traditional } \\
\text { culture or religion provide the self. }\end{array}$ \\
\hline Universalism & Broadmindedness, appreciation, and protection of nature and beauty. \\
\hline
\end{tabular}

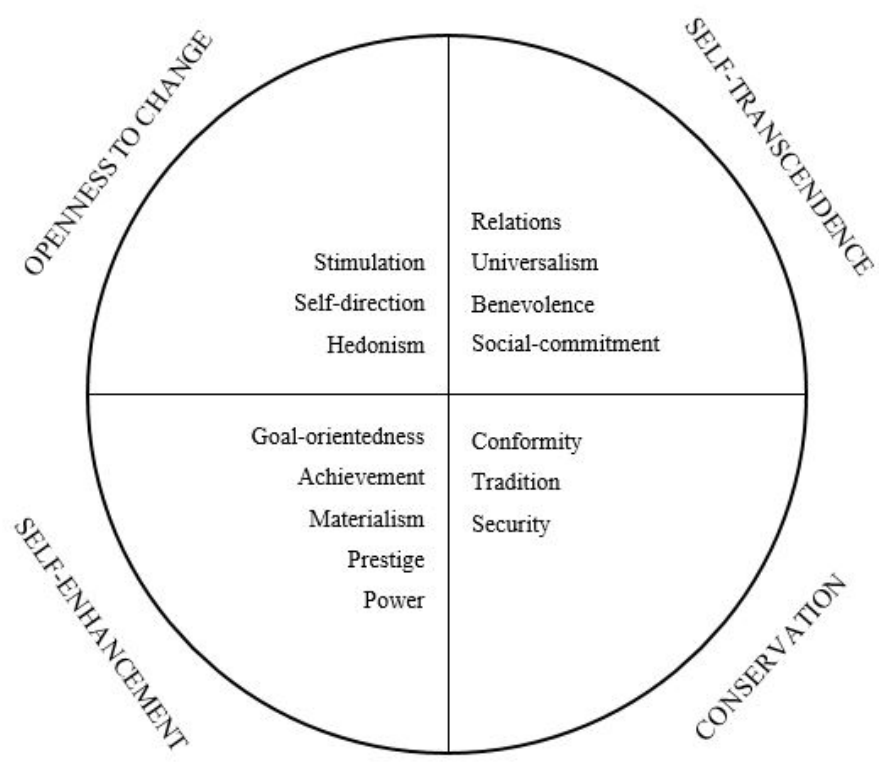

Figure 1: Theoretical model of relations among fifteen motivational types of values by De Clercq (2007) 
In order to have a comprehensive assessment of overall job satisfaction based on Lewin's (1951) interaction theory, two popular instruments were implemented: the Job Satisfaction Survey (JSS; Spector, 1997) and the Minnesota Satisfaction Questionnaire (MSQ; Weiss et al., 1967). Spector (1997) considers the nine dimensions of job satisfaction as the organizational factors derived from job and environment-related rewards which affect employees' job satisfaction (Emami et al., 2012). Furthermore, Weiss et al. (1967) believe that some personal characteristics motivate people to show different levels of satisfaction (Aziri, 2011). In total, 26 value items were considered to measure overall job satisfaction. In accordance with the nine dimensions of job satisfaction presented by Spector (1997), 23 value items were selected from the organisational values' profile. These items included: 1) Pay: "financial reward" and "financial security", 2) Promotion: "advancement", "successful", and "professional growth", 3) Supervision: "make decisions", "power", and "independence", 4) Fringe benefits: "personal security" and "stability", 5) Contingent rewards: "recognition", "to meet with appreciation", and "being admired", 6) Operating conditions: "being highly organized", "broadminded", and "flexibility", 7) Coworkers: "friendship" and "strong work relationships", 8) Nature of work: "efficiency", "enjoying work", "meaning in work", and "excitement", and 9) Communication: "leadership". In addition, 3 value items of "helpful", "accepting my job position", and "conformism" inspired by MSQ (Weiss et al., 1967) were chosen from the personal values profile.

The final version of the questionnaire consisted of 70 value items. In order to measure the responses, a Likert scale was used ranging from 1 (not important) to 5 (extremely important). Aside from the part allocated to the value survey in the questionnaire, a demographic section was embedded at the beginning of the questionnaire survey including ten items: 1) Gender, 2) Age, 3) Marital status, 4) Race, 5) Religion, 6) Profession, 7) Level of education, 8) Type of company, 9) Type of construction project, and 10) Type of company ownership. These demographic variables were selected to be assessed in the questionnaire according to their potential effects on personalorganizational values, conflict, and job satisfaction. The effects of the entire demographic variables were controlled in the related statistical analyses.

\section{Sampling and data collection}

Internal construction stakeholders are those who are members of the project coalition and directly participate in the project (Olander and Landin, 2005; Sutterfield, Friday-Stroud and Shivers-Blackwell, 2006). This research targeted professional project consultants including architects, engineers, and quantity surveyors as the internal stakeholders of construction organisations in Malaysia. They were selected as respondents of this research because they are the main players in projects. Main players are more likely than any other stakeholders to create difficulties in solving conflicts if no attention is paid to their values (Olander and Landin, 2005). Using online distribution, 5,156 questionnaires were sent to email addresses of the eligible respondents between March and August 2014 (5 months). The division was 2,166 professional engineers (42\%), 1,967 professional architects (38\%), and 1,023 professional quantity surveyors $(20 \%)$. In total, 627 questionnaires were received (12\% response rate), but according to screening criteria (missing, outliers and meaningless data) this number was reduced to 428 answered questionnaires. The minimum reliable sample size for this research with $95 \%$ confidence level was 400 respondents, referring to De Vaus (2013) who argued that for a large population, 400 respondents possess $5 \%$ sampling error which was considered in this research. Therefore, using stratified random sampling, 168 engineers, 152 architects, and 80 quantity surveyors were selected randomly. It must be noted that the number of respondents in each groups was based on their proportion in the aggregate population structure (42\% engineers, 38\% architects, and $20 \%$ quantity surveyors). Furthermore, the number of respondents was reduced from 428 to 400 in order to keep the presupposed proportional structure for each stratum in the sample size. 


\section{Analysis and discussion}

Figure 2 displays the conceptual framework of the research. This research investigated conflicts rooted in the differences between personal and organisational values, and the possible effect of conflicts on the job satisfaction of internal construction stakeholders. To attain the research purpose: 1) using descriptive statistics and comparative analysis, personal values of the construction stakeholders (architects, engineers, and quantity surveyors) and the organisational values of construction organisations were identified and possible conflicts between personalorganisational value profiles were determined, 2) the personal-organizational value conflicts were calculated using the methods implemented in the P-O fit studies, 3) the level of internal construction stakeholders' job satisfaction was specified using descriptive statistics through mean score, and 4) using hierarchical regression analyses, the possible effects of the calculated conflicts on job satisfaction of the internal construction stakeholders were evaluated. It must be noted that, according to the purpose of this research, personal and organisational values and conflict measures were considered as the independent variables and job satisfaction was considered as the dependent viable of this research. The statistical analyses in this research were performed by SPSS 22.

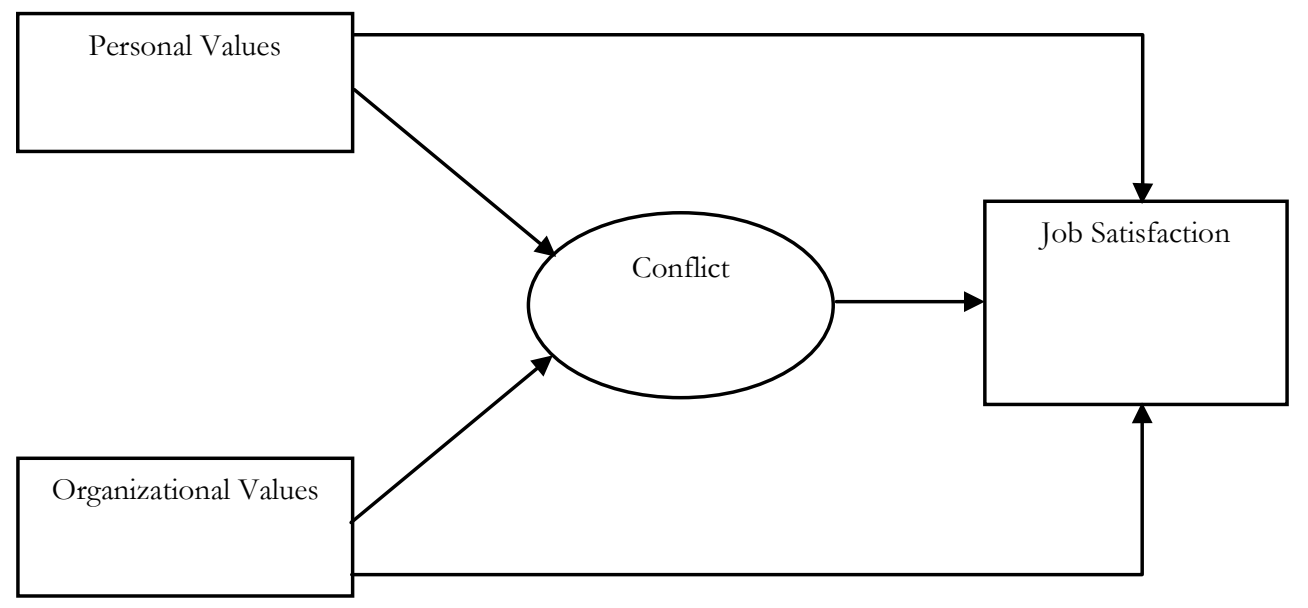

Figure 2: Conceptual framework of the research

\section{Descriptive statistics and comparative analysis of personal and organizational values}

The first step of analysis identified the potential conflicts between personal and organisational value profiles. Therefore, personal and organisational profiles were compared on the basis of the fifteen value types and the four higher-order value types considered by De Clercq (2007) to find any significant differences indicating value conflicts between the profiles. Table 2 reports the results generated by the T-test performed on the fifteen values. It must be noted that the personal values were labelled as $\mathrm{A}$, and the organisational values as $\mathrm{B}$. Furthermore, a positive ' $\mathrm{t}$ ' score indicates that the mean score belonging to the personal value is higher than the organisational value and vice versa for negative sign.

As Table 2 indicates, there were significant differences between the personal and the organisational values in ten value types of: benevolence, hedonism, materialism, prestige, relations, stimulation, conformity, power, achievement, and social-commitment. Conversely, there were good fits between the personal and the organisational values (P-O fit) in five value types of: security, universalism, self-direction, goal-orientedness, and tradition. Figure 3 depicts the comparison of personal and organisational value profiles on the basis of the fifteen value types. 
Table 2: Comparative analysis of personal and organisational values based on value types

\begin{tabular}{|c|c|c|c|c|c|}
\hline Pair & Value & Mean & $\begin{array}{c}\text { Std. } \\
\text { Deviation }\end{array}$ & $\mathbf{t}$ & Sig. \\
\hline \multirow{2}{*}{ Pair 1} & Stimulation A & 3.59 & 0.91 & \multirow{2}{*}{$-10.11 *$} & \multirow{2}{*}{0.03} \\
\hline & Stimulation B & 3.83 & 0.68 & & \\
\hline \multirow{2}{*}{ Pair 2} & Self-direction A & 3.64 & 0.82 & \multirow{2}{*}{-4.74} & \multirow{2}{*}{0.08} \\
\hline & Self-direction B & 3.79 & 0.75 & & \\
\hline \multirow{2}{*}{ Pair 3} & Hedonism A & 3.46 & 0.89 & \multirow{2}{*}{$29.09 * *$} & \multirow{2}{*}{0.00} \\
\hline & Hedonism B & 2.62 & 0.81 & & \\
\hline \multirow{2}{*}{ Pair 4} & Conformity A & 3.38 & 0.94 & \multirow{2}{*}{ 13.69* } & \multirow{2}{*}{0.02} \\
\hline & Conformity B & 3.09 & 0.69 & & \\
\hline \multirow{2}{*}{ Pair 5} & Tradition A & 2.89 & 0.95 & \multirow{2}{*}{7.91} & \multirow{2}{*}{0.0} \\
\hline & Tradition B & 2.67 & 0.75 & & \\
\hline \multirow{2}{*}{ Pair 6} & Security A & 3.47 & 0.89 & \multirow{2}{*}{-0.48} & \multirow{2}{*}{0.8} \\
\hline & Security B & 3.49 & 0.71 & & \\
\hline \multirow{2}{*}{ Pair 7} & Relations A & 3.51 & 0.84 & \multirow{2}{*}{$14.41 * *$} & \multirow{2}{*}{0.00} \\
\hline & Relations B & 3.20 & 0.84 & & \\
\hline \multirow{2}{*}{ Pair 8} & Universalism A & 3.32 & 0.86 & \multirow{2}{*}{-2.15} & \multirow{2}{*}{0.4} \\
\hline & Universalism B & 3.38 & 0.91 & & \\
\hline \multirow{2}{*}{ Pair 9} & Benevolence A & 3.60 & 0.85 & \multirow{2}{*}{$31.47^{* *}$} & \multirow{2}{*}{0.00} \\
\hline & Benevolence B & 2.70 & 0.77 & & \\
\hline \multirow{2}{*}{ Pair 10} & Social-commitment A & 3.41 & 0.94 & \multirow{2}{*}{$8.24 *$} & \multirow{2}{*}{$0.0^{2}$} \\
\hline & Social-commitment B & 3.19 & 0.72 & & \\
\hline \multirow{2}{*}{ Pair 11} & Goal-orientedness A & 3.49 & 0.80 & 681 & 006 \\
\hline & Goal-orientedness B & 3.69 & 0.81 & -0.01 & 0.00 \\
\hline Pair 12 & Achievement A & 3.83 & 0.93 & $873 *$ & $0 \Omega 4$ \\
\hline 12 & Achievement B & 4.05 & 0.67 & -0.15 & 0.04 \\
\hline Poir 13 & Materialism A & 3.37 & 0.84 & $1807 * *$ & 000 \\
\hline Fall 15 & Materialism B & 3.84 & 0.76 & $-10.0 / 7$ & 0.00 \\
\hline Pair 14 & Prestige A & 3.56 & 0.93 & $1503 * *$ & $0 \Omega 0$ \\
\hline 10 & Prestige B & 3.92 & 0.88 & $-15.93 \%$ & 0.00 \\
\hline Pair 15 & Power A & 3.53 & 0.91 & $-1262 *$ & 002 \\
\hline tare 10 & Power B & 3.80 & 0.66 & & \\
\hline
\end{tabular}

**. The mean difference is significant at the 0.01 level.

*. The mean difference is significant at the 0.05 level.

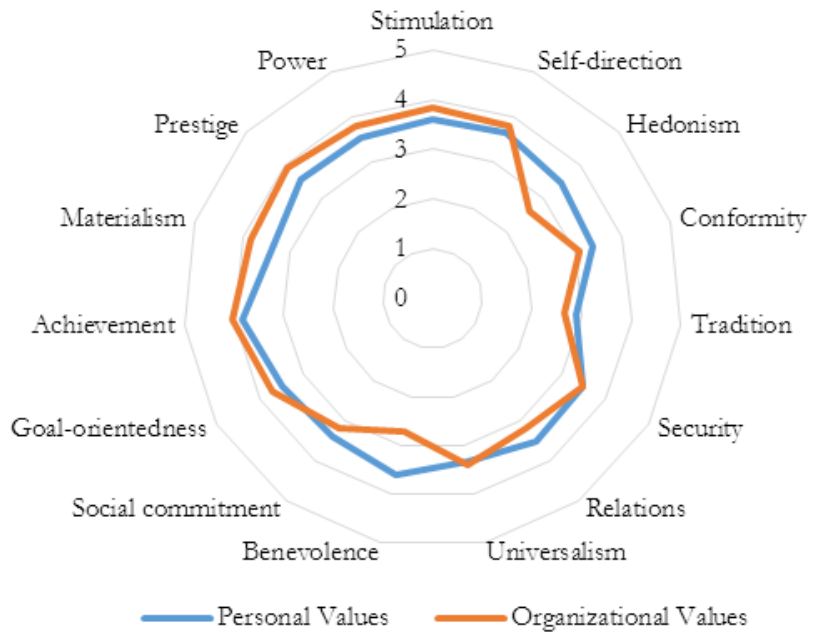

Figure 3: Comparison of personal and organisational values based on value types 
After comparing personal and organisational value profiles on the basis of the fifteen value types, the value profiles were evaluated based on the four higher-order values identified by De Clercq (2007). Table 3 reports the results generated by the comparative analysis of the personal and the organisational values.

Table 3: Comparative analysis of personal and organisational values based on higher-order value types

\begin{tabular}{|c|c|c|c|c|c|}
\hline Pair & Value & Mean & $\begin{array}{c}\text { Std. } \\
\text { Deviation }\end{array}$ & $\mathbf{t}$ & Sig. \\
\hline \multirow{2}{*}{ Pair 1} & Openness to Change A & 3.59 & 0.77 & \multirow{2}{*}{5.74} & \multirow{2}{*}{0.08} \\
\hline & Openness to Change B & 3.44 & 0.64 & & \\
\hline \multirow{2}{*}{ Pair 2} & Conservation A & 3.27 & 0.83 & \multirow{2}{*}{7.16} & \multirow{2}{*}{0.07} \\
\hline & Conservation B & 3.10 & 0.60 & & \\
\hline \multirow{2}{*}{ Pair 3} & Self-Transcendence A & 3.49 & 0.78 & \multirow{2}{*}{$14.05^{* *}$} & \multirow{2}{*}{0.00} \\
\hline & Self-Transcendence B & 3.15 & 0.72 & & \\
\hline \multirow{2}{*}{ Pair 4} & Self-Enhancement A & 3.62 & 0.79 & \multirow{2}{*}{$-11.17 *$} & \multirow{2}{*}{0.02} \\
\hline & Self-Enhancement B & 3.88 & 0.67 & & \\
\hline
\end{tabular}

**. The mean difference is significant at the 0.01 level.

*. The mean difference is significant at the 0.05 level.

As Table 3 indicates, there were significant conflicts between the personal values and the organisational values in two higher-order values of self-transcendence and self-enhancement. Furthermore, it can be postulated that there were good fits between the personal and the organisational values in two higher-order values of openness to change and conservation. Figure 4 depicts the comparison of personal and organisational value profiles on the basis of the four higher-order value types.

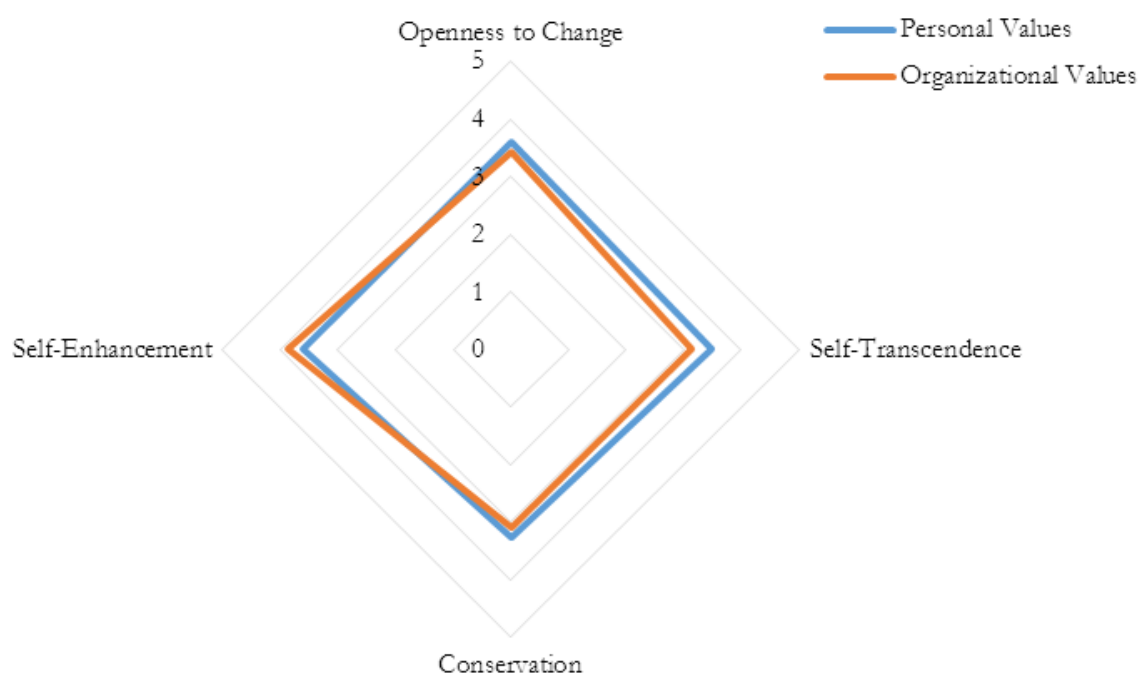

Figure 4: Comparing personal and organisational values based on higher-order value types

In general, the comparative analyses of personal and organisational value profiles based on the fifteen value types and the four higher-order value types considered by De Clercq (2007) comprehensive value model demonstrated a high level of value conflicts (in ten value types and two higher-order values) between the internal construction stakeholders and the culture prevalent in the construction organisations. 


\section{Calculation and descriptive statistics of conflict measures}

After the personal-organisational value conflicts were identified, the analytical process was continued in order to calculate the identified conflicts. In fact, this research focused on indirect conflict which was calculated using the methods applied for computing P-O fit in the previous research (e.g., Tepeci, 2001; Karakurum, 2005). Several methods were utilized to calculate P-O fit, among them; four different methods were selected to compute conflict in the current study. Three methods of difference scores and correlation score comprised the four measures of conflict. Difference between the value profiles was calculated by subtracting personal value scores from organisational value scores. The first measure of difference scores was computed by summing these differences, which was labelled as C. The second measure of difference scores was computed by summing the absolute differences between personal and organisational value profiles, which was denoted as $|\mathrm{C}|$. The last measure of difference scores was calculated by taking the squared differences of personal and organisational values, which was denoted as $\mathrm{C}^{2}$. In addition to them, correlation between the personal and the organisational value profiles was calculated for each respondent as a measure of conflict, which was labelled as Q. Table 4 presents means, standard deviations, and minimum and maximum values for each of the four measures.

Table 4: Descriptive statistics of conflict measures

\begin{tabular}{|ccccc|}
\hline & Mean & $\begin{array}{c}\text { Std. } \\
\text { Deviation }\end{array}$ & Minimum & Maximum \\
\cline { 2 - 5 } $\mathbf{C}$ & -12.20 & 22.10 & -99.76 & 46.25 \\
$|\mathbf{C}|$ & 61.69 & 13.45 & 39.39 & 114.10 \\
$\mathbf{C}^{2}$ & 81.17 & 31.87 & 33 & 209.10 \\
$\mathbf{Q}$ & -0.16 & 0.31 & -0.32 & 0.29 \\
\hline
\end{tabular}

The mean score of -12.20 in $\mathrm{C}$ demonstrated that, on the average, the levels of organisational values were lower than the levels of personal values. Minimum and maximum values of conflict indicated the range or how the smallest and largest values differ. In summary, according to the high values of $\mathrm{C},|\mathrm{C}|$, and $\mathrm{C}^{2}$, it can be realized that there were significant conflicts between the internal stakeholders' personal values and the organisational values of the construction organisations. In addition, the correlation of $r=-0.16$ corroborated a low and negative relationship between the internal stakeholders and the organisations, implying a dissimilar patterns of personal and organisational values. These findings were in line with the results generated by the comparative analysis of the personal and the organisational value profiles.

\section{Descriptive statistics of job satisfaction's variable}

The 26 value items considered to measure job satisfaction were averaged to make a composite scale score for this variable. Descriptive statistics of job satisfaction indicated a mean score of 3.05 and a normal standard deviation (0.75). The mean score suggested that respondents have had a moderate level of job satisfaction.

\section{Hierarchical regression analyses}

This study aimed to investigate the role of conflict in explaining the internal construction stakeholder's job satisfaction. Of particular interest was whether conflict explains variance above and beyond that explained by the organisational values and the personal values. To assess these relationships, hierarchical regression analyses were performed on two levels. First, hierarchical regression analyses were utilized to determine the contribution of each conflict measure over and above variables already entered in the equation (demographics, organisational values and 
personal values) and second, hierarchical regression analyses without considering the organisational and personal values variables.

Table 5: Hierarchical regression for the effects of demographic variables, organisational values, personal values and conflict variables, on job satisfaction

\begin{tabular}{|c|c|c|c|c|}
\hline & \multicolumn{4}{|c|}{ Job Satisfaction (JS) } \\
\hline & \multirow[b]{2}{*}{$\beta$} & \multirow[b]{2}{*}{$\mathbf{R}^{2}$} & \multicolumn{2}{|c|}{ Change } \\
\hline & & & $\overline{\mathbf{R}^{2}}$ & $\bar{F}$ \\
\hline Step 1: Demographics (D) & & $0.14(0.12)$ & 0.14 & $19.39 * *$ \\
\hline Gender & $-0.39 * *$ & & & \\
\hline Age & $0.18^{*}$ & & & \\
\hline Marital Status & 0.02 & & & \\
\hline Race & -0.08 & & & \\
\hline Religion & -0.04 & & & \\
\hline Profession & $0.47 * *$ & & & \\
\hline Level of Education & 0.09 & & & \\
\hline Type of Company & $0.17 *$ & & & \\
\hline Type of Construction Project & 0.08 & & & \\
\hline Type of Company Ownership & $0.16^{*}$ & & & \\
\hline Step 2: Organisational Values $(\mathrm{OV})$ & & $0.40(0.37)$ & 0.26 & $105.15^{* *}$ \\
\hline Stimulation & -0.04 & & & \\
\hline Self-direction & 0.08 & & & \\
\hline Hedonism & 0.06 & & & \\
\hline Conformity & $0.13^{*}$ & & & \\
\hline Tradition & -0.05 & & & \\
\hline Security & $0.33^{* *}$ & & & \\
\hline Relations & -0.03 & & & \\
\hline Universalism & 0.03 & & & \\
\hline Benevolence & 0.05 & & & \\
\hline Social commitment & -0.02 & & & \\
\hline Goal-orientedness & 0.09 & & & \\
\hline Achievement & $0.18^{*}$ & & & \\
\hline Materialism & 0.06 & & & \\
\hline Prestige & $0.25^{* *}$ & & & \\
\hline Power & $-0.21 * *$ & & & \\
\hline Step 3: Personal Values (PV) & & $046(0.45)$ & 0.06 & $5.63^{*}$ \\
\hline Stimulation & 0.05 & & & \\
\hline Self-direction & $0.16^{*}$ & & & \\
\hline Hedonism & 0.08 & & & \\
\hline Conformity & 0.06 & & & \\
\hline Tradition & -0.06 & & & \\
\hline Security & $0.12^{*}$ & & & \\
\hline Relations & $0.17 *$ & & & \\
\hline Universalism & 0.02 & & & \\
\hline Benevolence & 0.09 & & & \\
\hline Social commitment & $0.13^{*}$ & & & \\
\hline Goal-orientedness & 0.08 & & & \\
\hline Achievement & $0.15^{*}$ & & & \\
\hline Materialism & 0.04 & & & \\
\hline Prestige & -0.06 & & & \\
\hline Power & -0.03 & & & \\
\hline Step 4: Conflict & & & & \\
\hline $\mathrm{C}$ & -0.07 & $0.46(0.45)$ & 0.00 & 0.31 \\
\hline$|\mathrm{C}|$ & $-0.14 *$ & $0.52(0.50)$ & 0.06 & $5.14^{*}$ \\
\hline $\mathrm{C}^{2}$ & $-0.31 * *$ & $0.69(0.67)$ & 0.23 & $92.38^{* *}$ \\
\hline Q & $0.16^{*}$ & $0.53(0.51)$ & 0.07 & 7.77* \\
\hline
\end{tabular}

Note: $\mathrm{R}^{2}$ values in parenthesis are adjusted $\mathrm{R}$-square. $\mathrm{N}=400 ; * * \mathrm{p}<0.01$ and $* \mathrm{p}<0.05$ 
For conducting the first level of hierarchical regression analyses, the independent variables were entered into regression analysis in four steps to assess their effects on the dependent variable of job satisfaction. As Table 5 reports, the independent variables included: 1) demographics, 2) organisational values, 3) personal values, and 4) conflict variables. It must be noted that the conflict variables were entered in the equation one by one and separately. Accordingly, four regression models were developed to assess the effect of conflict measures $\left(C,|C|, C^{2}\right.$, and $\left.Q\right)$ on job satisfaction (JS), beyond that explained by demographic variables (D), organisational values $(\mathrm{OV})$, and personal values $(\mathrm{PV})$ :

1. $J S=b_{0}+b_{1} D+b_{2} O V+b_{3} P V+b_{4} C+e$

2. $J S=b_{0}+b_{1} D+b_{2} O V+b_{3} P V+b_{4}|C|+e$

3. $J S=b_{0}+b_{1} D+b_{2} O V+b_{3} P V+b_{4} C^{2}+e$

4. $J S=b_{0}+b_{1} D+b_{2} O V+b_{3} P V+b_{4} Q+e$

As Table 5 shows, demographic variables explained $14 \%$ of the variance $(F=19.39, p<0.01)$. Among the demographic variables, profession had the most contribution of variance $(\beta=0.47$, $p<0.01)$, after profession, gender allocated the second place to itself $(\beta=-0.39, p<0.01)$. Organisational values explained an additional $26 \%(F=105.15, p<0.01)$. In terms of the organisational values, security $(\beta=0.33, p<0.01)$, prestige $(\beta=0.25, p<0.01)$, and power $(\beta=-0.21$, $p<0.01)$ had the greatest effects on the variance respectively. Personal values added $6 \%(F=5.63$, $p<0.05)$ to the explanation of the variance. In terms of personal values, the beta coefficients demonstrated that relations $(\beta=0.17, p<0.05)$, self-direction $(\beta=0.16, p<0.05)$, and achievement $(\beta=0.15, p<0.05)$ respectively accounted for much of that amount of variance. For conflict measures which were entered into the equation separately, $\mathrm{C}$ did not explain any additional variance, $|\mathrm{C}|$ added $6 \%$ to the variance $(\beta=-0.14, p<0.05)$ and enhanced the aggregated variance to $52 \%\left(50 \%\right.$ for adjusted $\left.\mathrm{R}^{2}\right)$. $\mathrm{C}^{2}$ explained an additional $23 \%(\beta=-0.31, p<0.01)$ of the variance and increased the total variance to $69 \%$ (67\% for adjusted $\left.\mathrm{R}^{2}\right)$. Finally, the $\mathrm{Q}$ measure of conflict had an additional $7 \%(\beta=0.16, p<0.05)$ of the variance and enhanced the total variance to $53 \%$ $\left(51 \%\right.$ for adjusted $\left.\mathrm{R}^{2}\right)$.

To test the effect of conflict on job satisfaction without controlling the organisational and the personal values, four regression models were developed:

1) $J S=b_{0}+b_{1} D+b_{2} C+e$

2) $J S=b_{0}+b_{1} D+b_{2}|C|+e$

3) $J S=b_{0}+b_{1} D+b_{2} C^{2}+e$

4) $J S=b_{0}+b_{1} D+b_{2} Q+e$

Table 6 reports the results generated by the hierarchical regression analyses performed to assess the regression equations. The results indicated that the entire conflict measures significantly explained additional values to the variance. $\mathrm{C}$ added $6 \%(F=6.41, p<0.05),|\mathrm{C}|$ added $18 \%$ $(F=66.21, p<0.01), C^{2}$ added 31\% $(F=129.61, p<0.01)$, and $Q$ added 19\% $(F=71.15, p<0.01)$ to the variance.

The results generated by the hierarchical regression analyses confirmed that conflict was the predictor of job satisfaction beyond and without controlling the organisational and the personal values. According to the negative signs of $\beta$ (positive for Q) in conflict measures, it can be concluded that conflict significantly had negative relationships with job satisfaction. Therefore, the research hypothesis which implied there is a significant negative relationship between conflict and job satisfaction of the internal construction stakeholders was accepted. In fact, regression analyses proved that conflicts reduce job satisfaction which is in line with the findings of 
previewed research (Tepeci, 2001; Karakurum, 2005; De Clercq, 2007) whereas the positive relationship between fit and job satisfaction was demonstrated (considering the opposite functions of fit and conflict), as were the findings of the past research which argued that the construction team members' satisfaction diminishes as conflict escalates (e.g., De Dreu and Van Vianen, 2001; Leung, Ng and Cheung, 2002).

Table 6: Hierarchical regression for the effects of conflict variables on job satisfaction without controlling personal and organisational values

\begin{tabular}{|lccc|}
\hline & \multicolumn{3}{c|}{ Job Satisfaction (JS) } \\
\cline { 2 - 4 } & \multicolumn{3}{c|}{ Change } \\
\cline { 2 - 4 } & $\mathbf{R}^{2}$ & $\mathbf{R}^{2}$ & $\mathbf{F}$ \\
\cline { 2 - 4 } Demographics (D) & $0.14(0.13)$ & 0.14 & $19.56^{* *}$ \\
Conflict & & & \\
C & $0.20(0.19)$ & 0.06 & $6.41^{*}$ \\
$|C|$ & $0.32(0.31)$ & 0.18 & $66.21^{* *}$ \\
$C^{2}$ & $0.45(0.43)$ & 0.31 & $129.61^{* *}$ \\
Q & $0.33(0.32)$ & 0.19 & $71.15^{* *}$ \\
\hline
\end{tabular}

Note: $\mathrm{R}^{2}$ values in parenthesis are adjusted $\mathrm{R}$-square.

$\mathrm{N}=400 ; * * \mathrm{p}<0.01$ and $* \mathrm{p}<0.05$

\section{Conclusion}

This paper looked at the issue of value conflicts in the Malaysian construction industry. The effect of conflicts as the consequences of dissimilarity between personal and organisational values on the internal stakeholders' job satisfaction was assessed as the aim of the research. The research findings indicated that conflicts even beyond the effects of differences in demographics, personal and organisational values, have negatively affected job satisfaction of the internal construction stakeholders in Malaysia. It demonstrates that personal-organisational value conflict is a better and stronger predictor of job satisfaction than demographics, personal characteristics, organisational characteristics, or all three combined. This destructive effect of value conflicts on job satisfaction, according to the pivotal role of this attitudinal factor on the performance, commitment and motivation of the internal construction stakeholders, and therefore the efficiency and productivity of the construction projects, indicates the significance of values in explaining the success of the construction organisations. The importance of value-based management as a new paradigm in project management is thus conclusively revealed. This paper sincerely suggests that project managers pay more attention to the construct of "values" in the organisational setting, aiming to make a better fit between personal values of the construction stakeholders and the value system prevalent in the construction organisations. This would lead to reduced conflicts in projects and enhance the job satisfaction of construction stakeholders.

\section{References}

Adnan, H., Shamsuddin, S.M., Supardi, A. and Ahmad, N., 2012. Conflict Prevention in Partnering Projects. Procedia-Social and Behavioral Sciences, 35, pp.772-81. doi: http://dx.doi.org/10.1016/j.sbspro.2012.02.148

Aziri, B., 2011. Job Satisfaction: A literature Review. Management Research and Practice, 3(4), pp.7786. 
Bao, Y., Dolan, S.L. and Tzafrir, S.S., 2012. Value Congruence in Organizations: Literature Review, Theoretical Perspectives and Future Directions. ESADE working paper, n 239.

Brockman, J.L., 2012. The Cost of Interpersonal Conflict in Construction. PhD, Michigan State University, Michigan.

Cable, D.M. and Edwards, J.R., 2004. Complementary and Supplementary Fit: A Theoretical and Empirical Integration. Journal of Applied Psychology, 89(5), pp.822-34. doi: http://dx.doi.org/10.1037/0021-9010.89.5.822

Cammann, C., Fichman, M., Jenkins, D. and Klesh, J., 1979. Michigan Organizational Assessment Questionnaire. Unpublished Manuscript, University of Michigan, Ann Arbor, Michigan.

Chatman, J.A., 1989. Improving Interactional Organizational Research: A Model of PersonOrganization Fit. Academy of Management Review, 14(3), pp.333-49. doi: http://dx.doi.org/10.2307/258171 and http://dx.doi.org/10.5465/AMR.1989.4279063

Chatman, J.A., 1991. Matching People and Organizations: Selection and Socialization in Public Accounting Firms. Administrative Science Quarter, 36(3), pp.458-84. doi: http://dx.doi.org/10.2307/2393204

Daniela, P., Marius, B., Andreea-Ramona, L. and Oana-Alina, B., 2013. Personal Values and the Professional or Academic Performance in the Engineering Professions. Procedia-Social and Behavioral Sciences, 83, pp.743-47. doi: http://dx.doi.org/10.1016/j.sbspro.2013.06.140

De Clercq, S., 2007. Extending the Schwarts. Value Theory for Assessing Supplementary PersonOrganization Fit. PhD, Ghent University, Ghent.

De Dreu, C.K.W., and Van Vianen, A.E.M., 2001. Managing Relationship Conflict and the Effectiveness of Organisational Teams. Journal of Organisational Behavior, 22(3), pp.309-28. doi: http://dx.doi.org/10.1002/job.71

De Vaus, D., 2013. Surveys in Social Research. London: Routledge.

Drucker, P.F., 1988. Management and the World's Work. Harvard Business Review, 66(5), pp.65-76.

Duffy, R.D., 2010. Spirituality, Religion and Work Values. Journal of Psychology and Theology, 38(1), pp.52-61.

Emami, R., Moradi, E., Idrus, D., and Almutairi, D.O., 2012. Investigating the Relationship between Organizational Learning Culture, Job Satisfaction and Turnover Intention in It SMEs. International Journal of Innovative Ideas, 12(1), pp.8-23.

Enz, C.A., 1988. The Role of Value Congruity in Intraorganizational Power. Administrative Science Quarterly, 33(2), pp.284-304. doi: http://dx.doi.org/10.2307/2393060

Femi, O.T., 2014. Causes and Effects of Conflict in the Nigerian Construction Industry. International Journal of Technology Enhancements and Emerging Engineering Research, 2(6), pp.7-16.

Fenn, P., Lowe, D. and Speck, C., 1997. Conflict and Dispute in Construction. Construction Management and Economics, 15(6), pp.513-18. doi: http://dx.doi.org/10.1080/014461997372719

Hamid, S.N.A., and Yahya, K.K., 2011. Relationship between Person-Job Fit and PersonOrganization Fit on Employees' Work Engagement: A Study among Engineers in Semiconductor Companies in Malaysia. In Annual Conference on Innovations in Business and Management London. 6-9 June. UK, pp.1-30.

Hattrup, K., Mueller, K. and Joens, I., 2007. The Effects of Nations and Organizations on Work Value Importance: A Cross-Cultural Investigation. Applied Psychology: An International Review, 56(3), pp.479-99. doi: http://dx.doi.org/10.1111/j.1464-0597.2007.00268.x

Hellard, R.B., 1988. Managing Construction Conflict. England: Longman Group UK Ltd.

Ivancevich, J.M., Olekalns, M. and Matteson, M.T., 1997. Organizational behavior and Management. Sydney: Irwin.

Jaffar, N., Tharim, A.A., and Shuib, M.N., 2011. Factors of Conflict in Construction Industry: A Literature Review. Procedia Engineering, 20, pp.193-202. doi: http://dx.doi.org/10.1016/i.proeng.2011.11.142 and http://dx.doi.org/10.1016/i.proeng.2011.11.156

Jehn, K.A., 1997. To Agree or Not to Agree: The Effects of Value Congruence, Individual Demographic Dissimilarity, and Conflict of Workgroup Outcomes. International Journal of Conflict Management, 8(4), pp.287-305. doi: http://dx.doi.org/10.1108/eb022799 
Karakurum, M., 2005. The Effects of Person-Organization Fit on Employee Job Satisfaction, Performance and Organizational Commitment in a Turkish Public Organization. MSc., Middle East Technical University, Ankara.

Kennedy, M., 2005. An Integrative Investigation of Person-Vocation Fit, Person-Organization Fit, And Person-Job Fit Perceptions. PhD, University of North Texas, Texas.

Leung, M.Y., Ng, T. and Cheung, S.O., 2002. Improving Satisfaction through Conflict Stimulation and Resolution in Value Management in Construction Projects. Journal of Management in Engineering, 18(2), pp.68-75. doi: http://dx.doi.org/10.1061/(ASCE)0742$\underline{\text { 597X(2002)18:2(68) }}$

Leung, M.Y., Yu, J. and Liang, Q., 2013. Analysis of the Relationships between Value Management Techniques, Conflict Management and Workshop Satisfaction of Construction Participants. Journal of Management in Engineering, 30(3), pp.24-38.

Lewin, K., 1951. Field Theory in Social Science. New York: Harper.

Marzuki, P.F, Permadi, H. and Sunaryo, I., 2012. Factors Affecting Job Satisfaction of Workers in Indonesian Construction Companies. Journal of Civil Engineering and Management, 18(3), pp.299-309. doi: http://dx.doi.org/10.3846/13923730.2012.698889

Munson, J.M. and Posner, B.Z., 1979. The Values of Engineers and Managing Engineers. Engineering Management, IEEE Transactions, 5(4), pp.94-100.

O’Reilly, C.A., III, Chatman, J.A. and Caldwell, D.F., 1991. People and Organizational Culture: A Profile Comparison Approach to Assessing Person-Organization Fit. Academy of Management Journal, 34(3), pp.487-516. doi: http://dx.doi.org/10.2307/256404

Olander, S. and Landin, A., 2005. Evaluation of Stakeholder Influence in the Implementation of Construction Projects. International Journal of Project Management, 23(4), pp.321-28. doi: http://dx.doi.org/10.1016/j.ijproman.2005.02.002

Rokeach, M., 1979. Understanding Human Values. New York: Free Press.

Schein, E.H., 2011. Leadership and Organizational Culture. New York, NY: Wiley.

Schmidt, S., 2007. The Relationship between Satisfaction with Workplace Training and Overall Job Satisfaction. Human Resource Development Quarterly, 18(4), pp.481-98. doi: http://dx.doi.org/10.1002/hrdq.1216

Schneider, B., 2001. Fits about Fit. Applied psychology, 50(1), pp.141-52. doi: http://dx.doi.org/10.1111/1464-0597.00051

Schwartz, S.H., 1992. Universals in the Content and Structure of Values: Theoretical Advances and Empirical Tests in 20 Countries. In Zanna, M. (Ed.) Advances in Experimental Social Psychology (pp.1-65). Orlando, EL: Academic Press.

Schwartz, S.H. and Bilsky, W., 1987. Toward a Universal Psychological Structure of Human Values. Journal of Personality and Social Psychology, 53(3), pp.550-62. doi: http://dx.doi.org/10.1037/0022-3514.53.3.550

Smith, P.C., Kendall, L.M. and Hulin, C.L., 1969. The Measurement of Satisfaction in Work and Retirement. Chicago: Rand McNally.

Spector, P., 1997. Job Satisfaction: Application, Assessment, Causes, and Consequences. Thousand Oaks, CA: Sage Publications.

Suar, D. and Khuntia, R., 2010. Influence of Personal Values and Value Congruence on Unethical Practices and Work Behavior. Journal of Business Ethics, 97(3), pp.443-60. doi: http://dx.doi.org/10.1007/s10551-010-0517-y

Sutterfield, J.S., Friday-Stroud, S.S. and Shivers-Blackwell, S.L., 2006. A Case Study of Project and Stakeholder Management Failures: Lessons Learned. Project Management Quarterly, 37(5), pp.26-35.

Sverdlik, N., 2012. The Content of Internal Conflicts: A Personal Values Perspective. European Journal of Personality, 26(1), pp.30-44. doi: http://dx.doi.org/10.1002/per.814

Sweis, R.J., 2010. The Relationship between Information Technology Adoption and Job Satisfaction in Contracting Companies in Jordan. Journal of Information Technology in Construction, 15, pp.44-63. 
Tepeci, M., 2001. The effect of personal values, organizational culture, and person-organization fit on individual outcomes in the restaurant industry. $\mathrm{PhD}$, Pennsylvania State University, Pennsylvania.

Thomas, T.P., 2013. The Effect of Personal V alues, Organizational V alues, and Person-Organization Fit on Ethical Behaviors and Organizational Commitment Outcomes among Substance Abuse Counselors: A Preliminary Investigation. $\mathrm{PhD}$, University of Iowa, Iowa.

Thomson, D.S. and Austin, S.A., 2006. Using VALiD to understand value from the stakeholder perspective. Proceedings of 46th SAVE International Annual Conference. 4-7 June. Savannah, GA., pp.1-11.

Toh, S.M., Morgeson, F.P. and Campion, M.A., 2008. Human Resource Configurations: Investigating Fit with the Organizational Context. Journal of Applied Psychology, 93(4), pp.86482. doi: http://dx.doi.org/10.1037/0021-9010.93.4.864

Vansteenkiste, M., Neyrinck, B., Niemiec, C.P., Soenens, B., De Witte, H. and Van den Broeck, A., 2007. On the Relations among Work Value Orientations, Psychological Need Satisfaction and Job Outcomes: A Self-Determination Theory Approach. Journal of Occupational and Organizational Psychology, 80(2), pp.251-77. doi: http://dx.doi.org/10.1348/096317906X111024

Weiss, D.J., Dawis, R.V., England, G.W. and Lofquist, L.H., 1967. Manual for the Minnesota Satisfaction Questionnaire. Minnesota Studies in Vocational Rehabilitation, University of Minnesota.

Williams, R.M., 1979. Change and Stability in Values and Value Systems: A Sociological Perspective. In Rokeach, M. (Eds.) Understanding Human V alues (pp.15-46). New York: Free Press.

Williams, S.L., 2002. Strategic Planning and Organizational Values: Links to Alignment. Human Resource Development International, 5(2), pp.217-33. doi: http://dx.doi.org/10.1080/13678860110057638

Zouher Al-Sibaie, E., Mohammed Alashwal, A., Abdul-Rahman, H. and Kalsum Zolkafli, U., 2014. Determining the Relationship between Conflict Factors and Performance of International Construction Projects. Engineering, Construction and Architectural Management, 21(4), pp.369-82. doi: http://dx.doi.org/10.1108/ECAM-03-2014-0034 